\title{
Sistem Pendukung Keputusan Pemilihan Perumahan Terbaik dengan Metode TOPSIS
}

\author{
Ela Nurelasari" ${ }^{\# 1}$, Esty Purwaningsih ${ }^{\# 2}$ \\ ${ }^{\#}$ Sistem Informasi, Fakultas Tenik dan Informatika, Universitas Bina Sarana Informatika \\ Jl. Kamal Raya No.18, Ringroad Barat, Cengkareng, Jakarta Barat \\ 1ela.eur@bsi.ac.id \\ 2esty.epw@bsi.ac.id
}

\begin{abstract}
Abstrak
Semakin berkembangnya perusahaan developer property menjadikan calon pembeli akan kesulitan dalam memilih perumahan yang sesuai dengan kriteria yang diinginkan. Pemilihan tempat tinggal huni bisa dilihat dari beberapa kriteria diantaranya rumah harus sehat, nyaman dan aman. Dalam penelitian ini penulis mengambil data perumahan sebanyak tiga sampel perumahan di daerah Depok Jawa Barat. Dimana, tujuan dari penelitian ini membuat sistem pendukung keputusan(SPK) yang dapat membantu calon pembeli dalam pemilihan perumahan. Sistem pendukung keputusan berfungsi untuk membantu dalam pengambilan keputusan untuk memecahkan suatu masalah terutama berbagai masalah yang sangat kompleks dan tidak terstruktur. Dalam penelitian ini penulis menggunakan metode Technique for Order Preference by Similarity to Ideal Solution(TOPSIS) merupakan suatu metode yang memiliki konsep yang didasarkan pada kedekatan suatu alternatif terhadap solusi ideal yang disebut juga dengan nilai preferensi. Kriteria yang digunakan dalam pemilihan perumahan diantaranya $\operatorname{Harga}(\mathrm{H})$, Lokasi(L), Fasilitas Umum(FU), Perijinan(P), dan Desain Rumah(DR). Setelah dilakukan pengujian TOPSIS diketahui bahwa dari 3 sampel perumahan dihasilkan nilai preferensi yang lebih tinggi dengan nilai 0,6456, sehingga hasil keputusan pemilihan perumahan yang terbaik adalah Perumahan yang ke 3. Dengan demikian, metode TOPSIS mampu memberikan rekomendasi pemilihan perumahan terbaik dengan hasil perhitungan lebih cepat dan akurat sehingga informasi yang dihasilkan dapat digunakan sebagai pendukung keputusan.
\end{abstract}

Kata kunci: Sistem Pendukung Keputusan(SPK), Penentuan Pemilihan Perumahan, Metode TOPSIS

\section{Housing Selection Decision Support System Using the TOPSIS Method}

\begin{abstract}
The development of property development companies makes prospective buyers will have difficulty in choosing housing that meets the desired criteria. The choice of habitation to live can be seen from several criteria including the house must be healthy, comfortable and safe. In this study the authors took housing data of three housing samples in the area of Depok, West Java. Where, the purpose of this study is to make a decision support system (SPK) that can help prospective buyers in choosing housing. Decision support systems function to assist in making decisions to solve a problem, especially various problems that are very complex and unstructured. In this study the authors used the Technique for Order Preference by Similarity to Ideal Solution (TOPSIS) method which has a concept based on the proximity of an alternative to the ideal solution, also called the preference value. The criteria used in the selection of housing include Price (H), Location (L), Public Facilities (FU), Licensing (P), and Home Design (DR). After testing with TOPSIS it is known that from 3 housing samples produced a higher preference value with a value of 0.6456 , so that the best housing selection decision results are the 3rd Housing. Thus, the TOPSIS method is able to provide recommendations on the best housing selection with the results of calculations more quickly and accurately so that the information generated can be used as a decision support.
\end{abstract}

Keywords: Decision Support System, MADM, Determination of Housing Selection, TOPSIS Method

\section{Pendahuluan}


Prospek bisnis properti terus meningkat. Tingkat pertumbuhan ekonomi yang baik, turunnya suku bunga dan meningkatnya daya beli masyarakat menjadi faktor utama bangkitnya bisnis properti [1]. Calon pembeli tidak mudah dalam memilih perumahan, karena pengambilan keputusan yang terburu-buru tidak akan memberikan kepuasan yang diharapkan oleh calon pembeli. Dalam menentukan perumahan tempat tinggal membutuhkan pertimbangan [2] untuk mendapatkan kediaman yang sesuai harapan. Karena setiap orang mempunyai kemampuan yang berbeda-beda. Dalam hal ini, pengambilan keputusan pemilihan perumahan menjadi hal yang sangat penting bagi calon pembeli. Sebab setiap orang ingin memiliki rumah yang nyaman, aman dan strategis[3]. Sistem Penunjang Keputusan (SPK) merupakan sistem berbasis komputer interaktif yang membantu mengambil keputusan memanfaatkan data untuk menyelesaikan suatu masalah [4][5]. Departemen Kesehatan Republik Indonesia Direktorat Jenderal Pengendalian Penyakit dan Penyehatan Lingkungan pada tahun 2017 bahwa Rumah merupakan sebuah bangunan, tempat manusia tinggal dan melangsungkan kehidupannya [6]. Dalam penelitian ini penulis menggunakan metode Technique for Order Preference by Similarity to Ideal Solution(TOPSIS) yang merupakan suatu metode yang memiliki konsep dimana alternatif terpilih yang terbaik tidak hanya memiliki jarak terpendek dari solusi ideal terpendek, namun juga memiliki jarak terpanjang dari solusi ideal negatif [7]. TOPSIS merupakan metode pengambilan keputusan multi kriteria[8] yang pertama kali diperkenalkan oleh Yoon dan Hwang pada tahun 1981.

Algoritma TOPSIS merupakan algoritma sistem pendukung keputusan yang berfungsi untuk mempermudah proses pengambilan keputusan yang bisa melibatkan banyak atribut[9]. Sehingga dapat mempermudah dalam proses pemilihan perumahan karena hasil akhir dari metode TOPSIS adalah dapat ditentukan dalam bentuk ranking pada tiap-tiap alternatif. Kriteria dalam pemilihan perumahan diantaranya $\operatorname{Harga}(\mathrm{H})$, Lokasi(L), Fasilitas Umum(FU), Perijinan(P), Desain Rumah(DR) dan Kredibilitas Developer(KD). Semakin banyaknya kriteria yang harus dipertimbangkan[10] dalam proses pengambilan keputusan, maka semakin relatif sulit juga untuk mengambil keputusan terhadap suatu permasalahan. Tahapan dalam metode TOPSIS adalah menggambarkan alternatif dan kriteria ke dalam sebuah matriks, membuat matriks keputusan ternormalisasi, membuat pembobotan pada matriks yang telah dinormalsasi, membuat nilai solusi ideal positif(A+) dan solusi ideal negatif(A-), selanjutnya menghitung separation measure yang merupakan pengukuran jarak dari suatu alternatif ke solusi ideal positif dan solusi ideal negatif dan tahapan terakhir menghitung nilai preferensi untuk setiap alternatif dalam bentuk ranking dari tiap-tiap alternatif yang ada. Tujuan dari penelitian ini adalah membuat sistem pendukung keputusan dalam membantu memilih perumahan tempat tinggal yang nyaman, aman, strategis, terjangkau dan sesuai dengan kemampuan.

\section{Metode PENELITIAN}

Pada penelitian ini dilakukan tahapan-tahapan sebagai berikut:

\section{A. Teknik Pengumpulan Data}

Metode penelitian memberikan gambaran rancangan penelitian yang meliputi antara lain: prosedur dan langkahlangkah yang harus ditempuh, waktu penelitian, sumber data dan dengan langkah apa data-data tersebut diperoleh dan selanjutnya diolah dan dianalisis[11]

Teknik pengumpulan data yang penulis lakukan adalah sebagai berikut:

1) Wawancara(interview): Penulis melakukan wawancara kepada beberapa calon pembeli perumahan yang dilakukan dengan tatap muka dan tanya jawab langsung melalui penyebaran kuisioner.

2) Observasi(Observation): Penulis melakukan observasi secara langsung ke beberapa perusahaan developer property untuk mendapatkan informasiinformasi terkait dengan fasilitas-fasilitas, harga, perijinannya dan lain-lain.

3) Studi Pustaka(Library Research): Penulis melakukan tinjauan pustaka yaitu dengan mengumpulkan beberapa referensi melalui beberapa sumber seperti buku, jurnal ilmiah dan ebook yang mengacu pada metode TOPSIS.

\section{B. Metode Penelitian}

Metode Penelitian adalah langkah yang dimiliki dan dilakukan oleh peneliti dalam rangka untuk mengumpulkan informasi atau data serta melakukan investigasi pada data yang telah didapatkan tersebut[11].

Jenis penelitian dalam sistem pendukung keputusan untuk pemilihan perumahan dengan menggunakan Metode TOPSIS". SPK merupakan sistem informasi berbasis komputer interaktif dalam memecahkan masalah yang tidak terstruktur sehingga mendapatkan informasi kepada pengambil keputusan[12]. Teknik preferensi pesanan dengan kemiripan dengan solusi ideal(TOPSIS) adalah metode klasik untuk memecahkan masalah pengambilan keputusan multikriteria(MCDM)[13] [14]. Pengambilan keputusan merupaan proses memilih dari beberapa alternatif sehingga sesuai dengan tujuan yang akan dicapai[15]. Metode TOPSIS adalah salah satu metode yang digunakan untuk menyelesaikan masalah MADM[16]. TOPSIS juga salah satu metode yang praktis dan mudah dipahami dalam proses pengambilan keputusan dari suatu masalah[17], kelebihannya memiliki konsep yang sederhana, efisien dan efektif dalam perhitungannya sehingga mampu mengukur kinerja pada setiap alternatif.

Beberapa tahapan dalam melakukan perhitungan dengan Metode TOPSIS sebagai berikut:

1. Membuat matriks keputusan dengan proses normalisasi;

$$
r_{i j}=\frac{x_{i j}}{\sqrt{\sum_{i=1}^{m} x_{i j}^{2}}}
$$


Dengan $i=1,2 \ldots, m$ dan $j=1,2, \ldots, n$.

2. Menghitung nilai matriks normalisasi terbobot; Solusi ideal positif $\mathbf{A}^{+}$dan solusi ideal negatif $\mathbf{A}^{-}$ dapat ditentukan berdasarkan rating bobot ternormalisasi $\left(\mathbf{y}_{\mathbf{i j}}\right)$ sebagai:

$y_{i j}=w_{i r}$

Dengan $i=1,2 \ldots . ., m$ dan $j=1,2, \ldots, n$.

3. Menghitung nilai matriks dari solusi ideal positif dan juga matriks solusi ideal negatif $(\mathrm{A}+$ dan $\mathrm{A}-)$;

$$
A^{+}=\left(y 1^{+}, y 2^{+}, \ldots, y n^{+}\right)
$$

$A_{-}=\left(y 1^{+}, y 2^{+}, \ldots ., y n^{+}\right)$

Dengan:

$y i^{+}=\left\{\begin{array}{l}\max _{1} y_{i j} \\ \min _{1} y_{i j}\end{array}\right.$

Jika $\mathrm{j}$ adalah atribut keuntungan jika $\mathrm{j}$ adalah atribut biaya

$y i^{-}=\left\{\begin{array}{l}\max _{1} y_{i j} \\ \min _{1} y_{i j}\end{array}\right.$

Jika $\mathrm{j}$ adalah atribut keuntungan

jika $\mathrm{j}$ adalah atribut biaya

4. Menentukan jarak antara nilai alternatif dengan matriks dari solusi ideal positif dan solusi ideal negatif;

Jarak antara alternatif $\mathbf{D}_{\mathbf{i}}$ dengan solusi ideal positif dirumuskan sebagai:

$D i^{+}=\sqrt{\sum_{j=1}^{n}\left(y i^{+}-y_{i j}\right) 2 i=1,2}$

Jarak antara alternatif $\mathbf{A}_{\mathbf{i}}$ dengan solusi ideal negatif dirumuskan sebagai:

$D i^{-}=\sqrt{\sum_{j=1}^{n}\left(y i^{+}-y_{i j}\right) 2 i=1,2}$

5. Menentukan nilai preferensi atau nilai kedekatan tiap alternatif atau nilai preferensi dari solusi ideal. TOPSIS membutuhkan rating kinerja setiap alternatif $\mathbf{A}_{\mathbf{i}}$ pada setiap criteria $\mathbf{C j}$ yang ternormalisasi.

Nilai preferensi untuk setiap alternatif $\left(\mathbf{V}_{\mathbf{i}}\right)$ diberikan sebagai

$V x=\frac{D x-}{(\mathrm{Dx}-)+(\mathrm{Dx}+)}$

\section{HASIL DAN PEMBAHASAN}

Dalam penelitian ini, proses perhitungan menggunakan metode TOPSIS dengan ditentukan kriteria-kriteria dan memberikan bobot untuk kriteria masing-masing. data yang digunakan adalah data olahan hasil dari kuisioner dari calon customer dengan menggunakan 5 kriteria diantaranya adalah harga, lokasi, fasilitas umum, perijinan dan desain rumah (lihat Tabel I). Hasilnya akan dihitung dan diolah menggunakan metode Technique for Order Preference by Similarity to Ideal Solution (TOPSIS) sampai dengan menghasilkan nilai preferensi[7]. Survey dilakukan pada 3 perumahan sebagai perbandingan.

TABEL I

BOBOT TIAP KRITERIA

\begin{tabular}{|l|l|}
\hline Kriteria & Bobot \\
\hline Harga(H) & 4 \\
\hline Lokasi(L) & 4 \\
\hline Fasilitas Umum(FU) & 3 \\
\hline Perijinan(P) & 4 \\
\hline Desain Rumah(DS) & 3 \\
\hline
\end{tabular}

\section{Keterangan:}

Tidak Penting $=1$

Cukup Penting=2

Penting=3

Sangat Penting $=4$

Tahap selanjutnya menjelaskan nilai keputusan ternormalisasi pada setiap kriteria (Lihat Tabel II).

TABEL III

KEPUTUSAN TERNORMALISASI

\begin{tabular}{|c|c|c|c|c|c|}
\hline & $\begin{array}{c}\text { Har } \\
\text { ga } \\
(\mathbf{H})\end{array}$ & $\begin{array}{l}\text { Lokasi } \\
\text { (L) }\end{array}$ & $\begin{array}{c}\text { Fasilita } \\
\text { s } \\
\text { Umum } \\
\text { (FU) }\end{array}$ & $\begin{array}{c}\text { Perijina } \\
\text { n } \\
\text { (P) }\end{array}$ & $\begin{array}{r}\text { Desain } \\
\text { Rumah } \\
\text { (DS) }\end{array}$ \\
\hline P1 & 4 & 2 & 3 & 4 & 3 \\
\hline P2 & 3 & 3 & 3 & 4 & 3 \\
\hline P3 & 4 & 3 & 4 & 4 & 2 \\
\hline $\begin{array}{c}\text { Hasil } \\
\text { Pangka } \\
\text { t } \\
\text { Perkrit } \\
\text { eria }\end{array}$ & 41 & 22 & 4 & 48 & 22 \\
\hline $\begin{array}{c}\text { Akar } \\
\text { Hasil } \\
\text { Pangka } \\
\text { t } \\
\text { perkrite } \\
\text { ria }\end{array}$ & $\begin{array}{c}6,403 \\
1\end{array}$ & 4,6904 & 5,8309 & 6,9282 & 4,6904 \\
\hline
\end{tabular}

\section{Rumus Menormalisasikan}


(Data)

$\overline{\text { (akar hasil pangkat perkriteria) }}$

$\mathrm{R} 1.1=4: 6,4031=0,6246$

R2.2 $=3: 6,4031=0,4685$

R3.3=4:6,4031=0,6246

$\mathrm{R} 2.1=2: 4,6904=0,4264$

R2.2 $=3: 4,6904=0,6396$

R3.3=3:4,6904=0,6396

$\mathrm{R} 1.1=3: 5,8309=0,5145$

R2.2 $=3: 5,8309=0,5145$

R3.3 $=4: 5,8309=0,6860$

$\mathrm{R} 1.1=4: 6,9282=0,5773$

R2.2 $=4: 6,9282=0,5773$

R3.3 $=4: 6,9282=0,5773$

$\mathrm{R} 1.1=3: 4,6904=0,6396$

R2.2 $=3: 4,6904=0,6396$

R3.3=2:4,6904=0,4264

Data normalisasi dapat dilihat pada Tabel III.

TABEL IIIII

DATA TERNORMALISASI

\begin{tabular}{|l|c|c|c|c|c|}
\hline & $\begin{array}{c}\text { Harg } \\
\mathbf{a}(\mathbf{H})\end{array}$ & $\begin{array}{c}\text { Lokasi } \\
(\mathbf{L})\end{array}$ & $\begin{array}{c}\text { Fasilitas } \\
\text { Umum(F } \\
\mathbf{U})\end{array}$ & $\begin{array}{c}\text { Periji } \\
\text { nan(P } \\
\mathbf{~}\end{array}$ & $\begin{array}{c}\text { Desain } \\
\text { Rumah(D } \\
\text { S) }\end{array}$ \\
\hline P1 & 0,6246 & 0,4264 & 0,5145 & 0,5773 & 0,6396 \\
\hline P2 & 0,4685 & 0,6396 & 0,5145 & 0,5773 & 0,6396 \\
\hline P3 & 0,6246 & 0,6396 & 0,686 & 0,5773 & 0,4264 \\
\hline
\end{tabular}

\section{Membuat Normalisasi Berbobot}

(Data normalisasi) x (Bobot kriteria)

Data normalisasi berbobot dapat dilihat pada Tabel IV.

TABEL IVV

DATA NORMALISASI BERBOBOT

\begin{tabular}{|l|c|c|c|c|c|}
\hline & $\begin{array}{c}\text { Harga } \\
(\mathbf{H})\end{array}$ & $\begin{array}{c}\text { Lokas } \\
\text { i(L) }\end{array}$ & $\begin{array}{c}\text { Fasilitas } \\
\text { Umum(F } \\
\mathbf{U})\end{array}$ & $\begin{array}{c}\text { Perijinan } \\
(\mathbf{P})\end{array}$ & $\begin{array}{c}\text { Desai } \\
\mathbf{n} \\
\text { Ruma } \\
\mathbf{h}(\mathbf{D S})\end{array}$ \\
\hline P1 & 2,4984 & 0,8528 & 1,5435 & 2,0392 & 1,9188 \\
\hline P2 & 1,4055 & 1,9188 & 1,5435 & 2,0392 & 1,9188 \\
\hline P3 & 2,4984 & 1,9188 & 2,744 & 2,0392 & 0,8528 \\
\hline
\end{tabular}

Mencari nilai Max dan Min dari Normalisasi Berbobot (Lihat Tabel V).
TABEL V

NILAI MAX DAN MIN NORMALISASI BERBOBOT

\begin{tabular}{|l|l|l|l|l|l|}
\hline & $\begin{array}{l}\text { Harga } \\
\text { (H) }\end{array}$ & $\begin{array}{l}\text { Lokasi( } \\
\text { L) }\end{array}$ & $\begin{array}{l}\text { Fasilitas } \\
\text { Umum(F } \\
\text { U) }\end{array}$ & $\begin{array}{l}\text { Periji } \\
\text { nan(P } \\
\text { ) }\end{array}$ & $\begin{array}{l}\text { Desain } \\
\text { Rumah( } \\
\text { DS) }\end{array}$ \\
\hline P1 & 2,4984 & 0,8528 & 1,5435 & 2,0392 & 1,9188 \\
\hline P2 & 1,4055 & 1,9188 & 1,5435 & 2,0392 & 1,9188 \\
\hline P3 & 2,4984 & 1,9188 & 2,744 & 2,0392 & 0,8528 \\
\hline Max & 2,4984 & 1,9188 & 2,744 & 2,0392 & 1,9188 \\
\hline Min & 1,4055 & 0,8528 & 1,5435 & 2,0392 & 0,8528 \\
\hline
\end{tabular}

Kirteria bersifat Benefit adalah apabila nilainya makin besar makin baik maka $\mathrm{D}+=\max$ dan $\mathrm{D}-=\min$

Kriteria bersifat Cost adalah apabila nilainya nilainya makin kecil makin baik maka $\mathrm{D}+=\min$ dan $\mathrm{D}-=\max$

Mencari D+ D- pada setiap alternatif (Lihat Tabel VI dan VII).

TABEL VI

HASIL PERHITUNGAN D+

\begin{tabular}{|c|c|}
\hline D1 & 1,6054 \\
\hline D2 & 1,6234 \\
\hline D3 & 1,0659 \\
\hline
\end{tabular}

TABEL VII

HASIL PERHITUNGAN D-

\begin{tabular}{|l|l|}
\hline D1 & 1,5267 \\
\hline D2 & 1,5075 \\
\hline D3 & 1,9421 \\
\hline
\end{tabular}

Selanjutnya mencari Rumus V/Hasil

$$
\begin{aligned}
& V x=\frac{D x-}{(\mathrm{Dx}-)+(\mathrm{Dx}+)} \text {. } \\
& V 1=\frac{1,5267}{(1,5267)+(1,6054)}=0,4874 \\
& V 2=\frac{1,5075}{(1,5075)+(1,6234)}=0,4815 \\
& V 3=\frac{1,9421}{(1,9421)+(1,0659)}=0,6456
\end{aligned}
$$


Langkah selanjutnya adalah menentukan nilai preferensi tertinggi sampai dengan terendah sehingga diperoleh perengkingan alternatif (Lihat Tabel VIII).

TABEL VIII

PREFERENSI DAN RANGKING ALTERNATIF

\begin{tabular}{|c|c|c|}
\hline Alternatif & Preferensi & Rangking \\
\hline P1 & 0,4874 & 2 \\
\hline P2 & 0,4815 & 3 \\
\hline P3 & 0,6456 & 1 \\
\hline
\end{tabular}

Berdasarkan perhitungan dengan menggunakan metode TOPSIS dan tabel preferensi maka didapat nilai preferensi yang paling tinggi adalah 0,6456 dengan rangking 1 sehingga perumahan yang terbaik adalah Perumahan 3.

\section{KESIMPULAN}

Penelitian ini bertujuan untuk mengetahui perumahan terbaik dengan kriteria-kriteria yang sudah ditetapkan diantaranya kriteria $\operatorname{Harga}(\mathrm{H})$, Lokasi(L), Fasilitas Umum(FU), Perijinan(P) dan Desain Rumah(DS) dan menggunakan data sampel survey sebanyak 3 perumahan. Berdasarkan hasil analisa dengan menggunakan metode TOPSIS dihasilkan nilai preferensi yang paling tinggi 0,6456 perumahan ke 3, sehingga keputusan pemilihan perumahan terbaik bahwa perumahan 3 terbaik karena memiliki nilai preferensi yang paling tinggi. Oleh karena itu sistem pendukung keputusan yang dikembangkan dengan metode Technique for Order Preference by Similarity to Ideal Solution (TOPSIS) bisa membantu dalam pengambilan keputusan perumahan terbaik dengan hasil perhitungan lebih cepat dan akurat sehingga informasi yang dihasilkan dapat digunakan sebagai pendukung keputusan.

\section{DAFTAR PUSTAKA}

[1] P. S. Sasongko and A. Sugiharto, "Sistem Pendukung Keputusan Pemilihan Perumahan Menggunakan Metode TOPSIS Berbasis WEB," vol. 2, no. 2, pp. 1-8, 2013.

[2] M. Fatmawati, "PENERAPAN METODE ANALYTICAL HIERARCHY PROCESS ( AHP ) PADA SISTEM PEDUKUNG KEPUTUSAN PEMILIHAN PERUMAHAN DI KAWASAN KOTA MADYA MALANG," vol. 1, no. 1, 2017.

[3] A. E. Wijaya and S. Nurlaelah, "Sistem Pendukung Keputusan Pemilihan Perumahan Menggunakan Metode TOPSIS Berbasis ANDROID(Studi Kasus: Kecamatan Subang)," no. April, 2019.

[4] Sunarti, "Perbandingan Metode TOPSIS dan SAW Untuk Pemilihan Rumah Tinggal," 2018.

[5] F. Anggraini and Jasmir, "Analisis dan Perancangan Sistem Pendukung Keputusan Rekomendasi Pemilihan Perumahan Dengan Metode TOPSIS (Studi Kasus: PT.Nasaliyasah)," vol. 1, no. 2, 2016.

[6] Kementrian Kesehatan RI Profil Kesehatan Indonesia. 2017.

[7] N. G. Perdana and T. Widodo, "Sistem Pendukung Keputusan Pemberian Beasiswa Kepada Peserta Didik Baru Menggunakan Metode TOPSIS,” vol. 2013, no. November, pp. 265-272, 2013.

[8] M. R. Syahputra, "Aplikasi fuzzy-topsis dalam melakukan seleksi pemilihan perumahan," vol. 15, no. 1, 2014

[9] T. P. Handayani, "Implementasi Algoritma Topsis Pada Pemilihan Rumah Hunian Di Provinsi Dan Kabupaten Gorontalo,” vol. 3, no. 1, pp. 1-6, 2016.
[10] H. Sugiarto, "PENERAPAN METODE SIMPLE ADDITIVE WEIGHTING UNTUK PEMILIHAN PERUMAHAN," vol. 1, no. 1, pp. 96-103, 2016.

[11] A. Hidayat, "METODE PENELITIAN: Pengertian, Tujuan, Jenis Uji Statistik," Www.Statistikian.Com, 2017.

[12] A. A. Chamid, "PRIORITAS KONDISI RUMAH," vol. 7, no. 2, pp. 537-544, 2016.

[13] A. Ramadhani, R. Santoso, and R. Rahmawati, "Pemilihan Perumahan Terfavorit Menggunakan Metode VIKOR dan TOPSIS dengan GUI Matlab(Studi Kasus: Perumahan Mijen Semarang)," vol. 8, no. Mcdm, pp. 330-342, 2019.

[14] D. Wu and D. L. Olson, "A TOPSIS Data Mining Demonstration and Application to Credit Scoring," vol. 2, no. September, pp. 1$10,2006$.

[15] E. Turban, J. E. Aronson, and T. Liang, "Decision Support Systems and."

[16] H. Hertyana, "Sistem pendukung keputusan penentuan karyawan terbaik menggunakan metode topsis," vol. 4, no. 1, pp. 43-48, 2018.

[17] A. H. Prasetyo, I. Cholissodin, and E. Santoso, "Rekomendasi Pemberian Kredit Pemilikan Rumah ( KPR ) Pada Nasabah Bank Menggunakan Metode AHP - Topsis," vol. 3, no. 2, 2019. 